\title{
Dairy- and supplement-based calcium intake in adulthood and vertebral dimensions in midlife-the Northern Finland Birth Cohort 1966 Study
}

\author{
P. Oura ${ }^{1,2,3} \cdot$ J. Auvinen ${ }^{1,2} \cdot$ M. Paananen ${ }^{1,2} \cdot$ J.-A. Junno ${ }^{1,4} \cdot$ J. Niinimäki ${ }^{1,3} \cdot$ J. Karppinen ${ }^{1,2,5} \cdot$ M. Nurkkala ${ }^{1,2,6}$
}

Received: 31 July 2018 / Accepted: 4 January 2019 / Published online: 17 January 2019

(C) The Author(s) 2019

\begin{abstract}
Summary Among a representative sample of 1064 Northern Finns, we studied the association of dairy- and supplementbased calcium intake in adulthood with vertebral size in midlife. Inadequate calcium intake $(<800 \mathrm{mg} / \mathrm{day})$ from age 31 to 46 predicted small vertebral size and thus decreased spinal resilience among women but not men.

Introduction Small vertebral size predisposes individuals to fractures, which are common among aging populations. Although previous studies have associated calcium (Ca) intake with enhanced bone geometry in the appendicular skeleton, few reports have addressed the axial skeleton or the vertebrae in particular. We aimed to investigate the association of dairy- and supplement-based $\mathrm{Ca}$ intake in adulthood with vertebral cross-sectional area (CSA) in midlife. Methods A sample of 1064 individuals from the Northern Finland Birth Cohort 1966 had undergone lumbar magnetic resonance imaging at the age of 46 , and provided self-reported data on diet and $\mathrm{Ca}$ intake (dairy consumption and use of $\mathrm{Ca}$ supplements) at the ages of 31 and 46 . We assessed the association between $\mathrm{Ca}$ intake (both continuous and categorized according to local recommended daily intake) and vertebral CSA, using generalized estimating equation and linear regression models with adjustments for body mass index, diet, vitamin D intake, education, leisure-time physical activity, and smoking.

Results Women with inadequate Ca intake $(<800 \mathrm{mg} /$ day) over the follow-up had 3.8\% smaller midlife vertebral CSA than women with adequate $\mathrm{Ca}$ intake $(p=0.009)$. Ca intake among men showed no association with vertebral CSA.

Conclusions Inadequate $\mathrm{Ca}$ intake $(<800 \mathrm{mg} / \mathrm{day})$ from the age of 31 to 46 predicts small vertebral size and thus decreased spinal resilience among middle-aged women. Future studies should confirm these findings and investigate the factors underlying the association of low $\mathrm{Ca}$ intake in women but not in men with smaller vertebral size.
\end{abstract}

Keywords Calcium intake $\cdot$ Cohort study $\cdot$ Diet $\cdot$ Lumbar spine $\cdot$ Magnetic resonance imaging $\cdot$ Vertebra

Electronic supplementary material The online version of this article (https://doi.org/10.1007/s00198-019-04843-9) contains supplementary material, which is available to authorized users.

P. Oura

petteri.oura@oulu.fi

1 Medical Research Center Oulu, Oulu University Hospital and University of Oulu, P.O. Box 5000, FI-90014 Oulu, Finland

2 Center for Life Course Health Research, Faculty of Medicine, University of Oulu, P.O. Box 5000, FI-90014 Oulu, Finland

3 Research Unit of Medical Imaging, Physics and Technology, Faculty of Medicine, University of Oulu, P.O. Box 5000, FI-90014 Oulu, Finland
4 Cancer and Translational Medicine Research Unit, Faculty of Medicine, University of Oulu, P.O. Box 5000, FI-90014 Oulu, Finland

5 Finnish Institute of Occupational Health, Aapistie 1, FI-90220 Oulu, Finland

6 Department of Sports and Exercise Medicine, Oulu Deaconess Institute, P.O. Box 365, FI-90101 Oulu, Finland 


\section{Introduction}

Vertebral fractures, one of the most typical complications of osteoporosis, are notoriously common among aging populations [1-3]. Vertebral dimensions have been associated with vertebral fracture risk as individuals with small vertebral size seem to be at an elevated risk of sustaining a morphometrically diagnosed vertebral fracture $[4,5]$. While previous research has shown that lifestyle choices in adulthood may influence vertebral size [6-8], the need has arisen to expand current knowledge on the factors affecting one's vertebral size across the life course.

From the nutritional point of view, calcium $(\mathrm{Ca})$ has attracted the most scientific interest in skeletal research, together with vitamin $\mathrm{D}[9,10]$. Achieving a sufficient Ca intake from diet is essential for skeletal health, not only in childhood and adolescence, when peak bone mass is accumulated [11], but also in later life, when $\mathrm{Ca}$ apparently contributes to preventing bone loss and microstructure degradation [12]. Although several studies have associated $\mathrm{Ca}$ intake with enhanced bone geometry at various skeletal sites [13-16], contradicting results have also been found [17]. Regarding the lumbar spine, we found only one study that addressed the association between $\mathrm{Ca}$ intake and vertebral size [17]: among 111 men aged $\geq 50$ years, 2 -year consumption of Ca-vitaminD-fortified milk had no effect on the geometry of L1-L3. Thus, the association between $\mathrm{Ca}$ and bone geometry requires further study; studies addressing vertebral geometry should be of particular interest due to the high incidence of vertebral fractures among the elderly $[2,3]$.

In the present study, we investigated the relationship between self-reported (dairy- and supplement-based) Ca intake at 31 and 46 years and vertebral cross-sectional area (CSA) at 46 years in a large, representative Finnish birth cohort population. We hypothesized that inadequate $\mathrm{Ca}$ intake would be associated with small vertebral CSA in midlife.

\section{Methods}

\section{Study sample}

We used a magnetic resonance imaging (MRI)-scanned subsample of the Northern Finland Birth Cohort 1966 (NFBC1966) as the study population. Figure 1 is a flow chart presenting the progression of the study and the specifications for exclusion. As a prospective population-based birth cohort study, the NFBC1966 included Northern Finnish children whose expected birth date was during the calendar year of 1966 [18]. Initial data collections covered 12,231 children, i.e., $96.3 \%$ of births in Northern Finland. Major follow-ups have taken place at 31 and 46 years and have covered the entire cohort. Moreover, those who attended the 46-year clinical examinations and lived in the Oulu region (radius of $100 \mathrm{~km}$ from the city of Oulu) were invited to a lumbar MRI scan at the age of 46 . We have previously shown that the MRI sample is representative of the general Northern Finnish population [19]. After all exclusions were completed, the final sample comprised 1064 individuals (Fig. 1). Bone-affecting medications were not reported in the sample.

\section{Vertebral dimensions at age 46 (outcome)}

Vertebral dimensions were measured from lumbar MRI scans. As described in our previous publication [7], MRI scans were obtained using a 1.5 T system (Signa HDxt, General Electric, Milwaukee, WI, USA) and a conventional lumbar spine protocol, i.e., T2-weighted fast-recovery fast spin-echo images in sagittal and transverse planes. The sagittal parameters were: repetition time $3500 \mathrm{~ms}$, effective echo time $112 \mathrm{~ms}$, 4 averages, field-of-view $280 \times 280 \mathrm{~mm}$, acquisition matrix $448 \times$ 224, slice thickness $3 \mathrm{~mm}$, and interslice gap $1 \mathrm{~mm}$. The transverse parameters were: repetition time 3600 , effective echo time $118 \mathrm{~ms}, 4$ averages, field-of-view $180 \times 180 \mathrm{~mm}$, acquisition matrix $256 \times 224$, slice thickness $4 \mathrm{~mm}$, and interslice gap $1 \mathrm{~mm}$.

Using NeaView Radiology software version 2.31 (Neagen Oy, Oulu, Finland), one researcher (P.O.) measured two widths (maximum, minimum) and three depths (cranial, caudal, midway) of each applicable L4, as demonstrated in Fig. 2. These dimensions have been previously presented and used in several similar studies [7, 8, 20-24]. Each dimension was documented to an accuracy of $0.1 \mathrm{~mm}$. The CSA of L4 was calculated as CSA $\left(\mathrm{mm}^{2}\right)=\pi \times a / 2 \times b / 2$, where $a=$ mean of width measurements and $b=$ mean of depth measurements. The formula has been validated [25] and used earlier in similar studies $[7,8,20-22,24]$. We have previously demonstrated that our MRI-derived vertebral measurements are accurate [24]. The intra-rater reliability of our measurement process has been high and measurement errors low [7]. We chose L4 due to its caudal location in the spine and due to higher stability than L5 [26]. L4 has been used in many previous studies $[7,8,20,21]$, and its results seem to be generalizable over other thoracolumbar vertebrae $[7,27]$.

\section{Calcium intake at age 31 and 46 (exposure)}

Calcium intake was approximated on the basis of self-reported dairy consumption and the use of Ca supplements. Dairy consumption in Finland is generally high [28], which provides an ideal setting for studying dairy-based Ca intake [29].

In the questionnaires, dairy consumption was elicited by asking "How many glasses $(0.2 \mathrm{~L})$ do you usually drink/eat per day of: (1) milk, (2) sour milk, (3) other dairy products (e.g., yoghurt, other fermented milk products, ice cream)?" and "How many slices of cheese do you eat per day?" The 
Fig. 1 Flow chart of the study

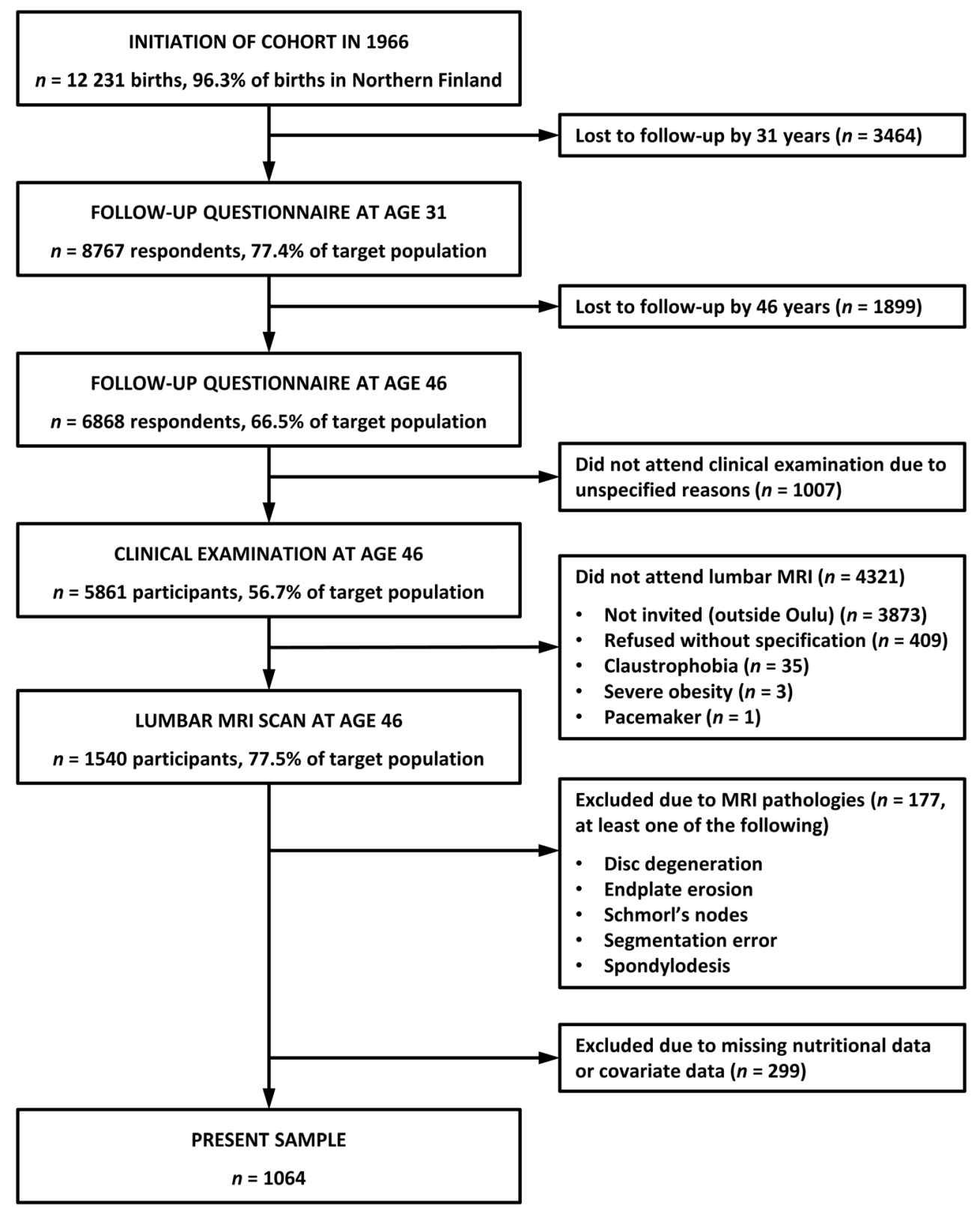

31- and 46-year questionnaires were identically formulated with the exception that the 46-year questionnaire elicited cheese consumption separately for low-fat $(\leq 17 \%)$ and normal fat $(>17 \%)$ cheeses. The use of Ca supplements was elicited by asking "Please list all your current medications together with their strength and dosage;" the respondents were instructed to also report vitamins and dietary supplements here.

According to the National Food Composition Database in Finland [30], maintained by the Finnish National Institute for Health and Welfare, 0.2 L of milk, sour milk, yoghurt, and other dairies contain $240 \mathrm{mg}$ of $\mathrm{Ca}$. Correspondingly, an average-sized slice of cheese ( $8 \mathrm{~g} \mathrm{[31])} \mathrm{contains} 75 \mathrm{mg}$ of $\mathrm{Ca}$ [30]. The overall $\mathrm{Ca}$ intakes (mg/day) at the ages of 31 and 46 were calculated as these dietary components and $\mathrm{Ca}$ supplements. Other sources of Ca (e.g., plant-based "milks" enriched with $\mathrm{Ca}$, nuts, seeds, soya, fish) were not assessed because their consumption was not elicited in enough detail in the food questionnaires, and because they yield relatively little of the daily Ca supply of Finns [32].

According to Finnish [33] and Nordic [34] nutrition recommendations, the recommended daily intake (RDI) of $\mathrm{Ca}$ is $800 \mathrm{mg}$ for the general adult population. At both time points, Ca intake was considered "adequate" ( $\geq 800 \mu \mathrm{g} /$ day $)$ or "inadequate" ( $<800 \mu \mathrm{g} /$ day). In addition, based on their longitudinal $\mathrm{Ca}$ intake in adulthood, we classified the individuals into "adequate" ( $\geq 800 \mathrm{mg} /$ day at both time points), "ascending" (<800 mg/day at 31 years, $\geq 800 \mathrm{mg} /$ day at 


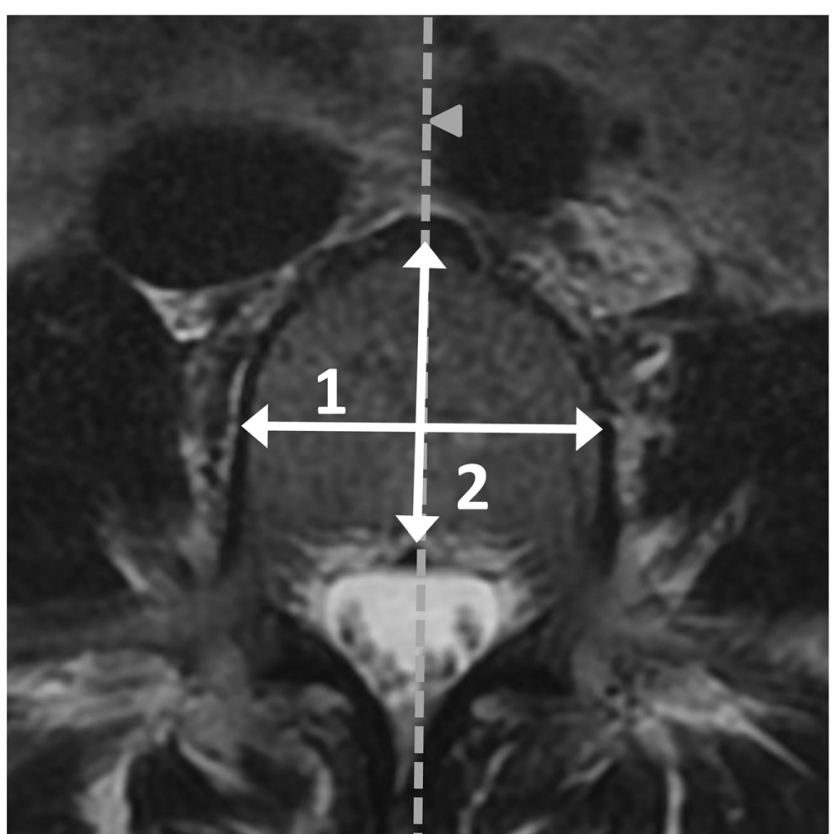

Fig. 2 Annotated MRI scan of L4. 1 = width, 2 = depth. After all axial planes were scanned, we measured the maximum and minimum widths and the cranial, caudal, and midaxial depths

46 years), "descending" ( $\geq 800 \mathrm{mg} /$ day at 31 years, $<800 \mathrm{mg} /$ day at 46 years $)$, and "inadequate" $(<800 \mathrm{mg}$ /day at both time points) categories, as illustrated in Fig. 3.

\section{Vitamin D intake at age 31 and 46 (confounder)}

Vitamin D intake was assessed using food questionnaires and data on vitamin D supplement use from the ages of 31 and 46. At the age of 31 , vitamin D intake was approximated on the basis of fish consumption and vitamin D supplements. Due to changes in the Finnish national vitamin D fortification policy between the two follow-ups (i.e., 1998 and 2012) [35], dairy products and bread spreads (i.e., margarines and vegetable oil spreads) were also taken into account as significant sources of vitamin $\mathrm{D}$ at the age of 46 .

In the 31- and 46-year food questionnaires, we elicited fish consumption by asking "How often do you usually consume

\section{LONGITUDINAL CALCIUM/VITAMIN D INTAKE}

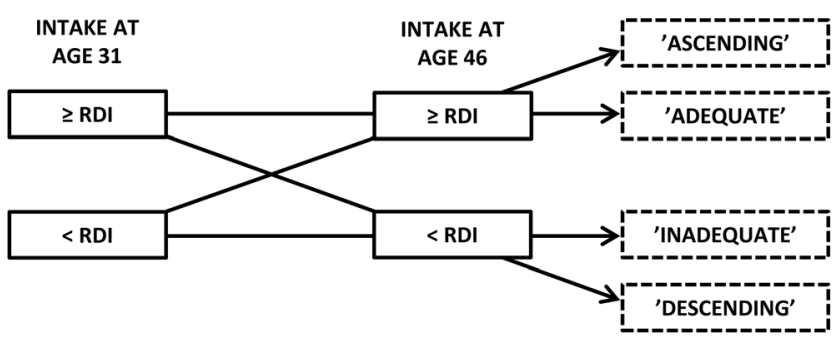

Fig. 3 Classification of individuals into groups on the basis of their $\mathrm{Ca} /$ vitamin $\mathrm{D}$ intake at ages of 31 and $46 . R D I$ recommended daily intake (for $\mathrm{Ca}, 800 \mathrm{mg} /$ day; for vitamin D, $10 \mu \mathrm{g} /$ day) fish or fish dishes? (1) less than once a month or not at all, (2) once or twice a month, (3) once a week, (4) twice a week, (5) almost daily, (6) daily or more often." The 31- and 46-year questionnaires were identically formulated with the exception that the 46-year questionnaire elicited the consumption of fatty, semi-fatty, and lean fish separately.

According to the National Food Composition Database [30,31], ten commonly consumed fish in Finland (pike, perch, vendace, Baltic herring, salmon, tuna, rainbow trout, saithe, whitefish, and zander) yield an average of $13.4 \mu \mathrm{g}$ of vitamin D per average-sized portion (140-160 g depending on the species). Thus, eating fish almost every day or more often was approximated as yielding an average vitamin D intake of $13.4 \mu \mathrm{g} /$ day. Correspondingly, eating fish twice a week was estimated to yield an average of $3.8 \mu \mathrm{g}$ of vitamin D per day; once a week yielded $1.9 \mu \mathrm{g} / \mathrm{day}$; and once or twice a month or less often was approximated as yielding $0 \mu \mathrm{g}$ of vitamin $\mathrm{D}$ per day.

The consumption of bread spreads was elicited by the following questions at the age of 46 :

1) "What type of bread spread do you usually use? (choose one category)" with pictures of common Finnish bread spread brands divided into seven categories: vegetable oil spreads with $23-40 \%$ fat, vegetable oil spreads with 60 $70 \%$ fat, mixture of organic butter and vegetable oil with $75 \%$ fat, mixture of butter and vegetable oil with $40-80 \%$ fat, organic butter, butter, plant-based sterol, and stanol margarines with $32-60 \%$ fat.

2) "How much spread do you usually put on a slice of bread? (choose one picture)" with actual-sized pictures of bread slices with $3,5,9$, and $12 \mathrm{~g}$ of spread.

3) "How many slices of bread do you usually have per day: rye breads, mixed breads and baguettes, white breads and baguettes?"

The average consumption of bread spread per day was calculated for each individual according to the number of bread slices consumed and the amount of bread spread used. Based on the National Food Composition Database [30], the amount of vitamin $\mathrm{D}$ was considered to vary depending on spread type as follows: butter and organic butter $0 \mu \mathrm{g}$ of vitamin D per $1 \mathrm{~g}$, vegetable oil spreads and plant-based sterol and stanol margarines $0.2 \mu \mathrm{g} / \mathrm{g}$, and mixtures of butter/organic butter and vegetable oil $0.1 \mu \mathrm{g} / \mathrm{g}$. These data enabled us to calculate the average daily intake of vitamin D from bread spreads for each individual.

The consumption of dairy products and the use of vitamin D supplements were elicited using the same questions as those presented above. According to the National Food Composition Database [30], all dairy products (except for cheese) were approximated as yielding $1 \mu \mathrm{g}$ of vitamin D per $100 \mathrm{~mL} / 100 \mathrm{~g}$. 
Overall vitamin D intake ( $\mu \mathrm{g} /$ day) at the ages of 31 and 46 was calculated as the sum of these dietary components and vitamin D supplements. According to Finnish [33] and Nordic [34] nutrition recommendations, the RDI of vitamin D is $10 \mu \mathrm{g} /$ day for the general adult population. At both time points, vitamin D intake was considered "adequate" ( $\geq$ $10 \mu \mathrm{g} /$ day) or "inadequate" (<10 $\mathrm{g}$ /day). In addition, similarly to the longitudinal $\mathrm{Ca}$ categorization, individuals were classified into "adequate," "ascending," "descending," and "inadequate" vitamin D intake groups, as illustrated in Fig. 3.

\section{Other confounders}

We considered the following variables to be confounding factors: body mass index (BMI), general diet, vitamin D intake, education, leisure-time physical activity, and smoking. At the 46-year clinical examination, the height $(\mathrm{cm})$ and weight $(\mathrm{kg})$ of the participants were systematically measured by a study nurse to an accuracy of $0.1 \mathrm{~cm} / 0.1 \mathrm{~kg}$. BMI was calculated as weight $(\mathrm{kg}) /$ height squared $\left(\mathrm{m}^{2}\right)$. Lifetime smoking classification ("non-smoker," "former smoker," "current smoker") was based on the responses to the questions "Have you ever smoked cigarettes (yes/no)?" and "Do you currently smoke (yes/no)?" Education years (<9 years, 9-12 years, > 12 years), indicative of socioeconomic status, were classified according to the responses to the questions "What is your basic education? (1) Less than nine years of elementary school, (2) elementary school, (3) attainment of matriculation examination" and "What is your vocational education? (1) None, (2) occupational course, (3) vocational school, (4) vocational college, (5) polytechnic, (6) university, (7) other, (8) unfinished course." Leisure-time physical activity $(<1,1,2-3, \geq 4$ times a week) was based on self-reported physical activity during leisure-time in the 46-year questionnaire: (1) daily, (2) 4-6 times a week, (3) 2-3 times a week, (4) once a week, (5) 23 times a month, (6) once a month or less often. All these variables have been introduced in our earlier publication [7]. General diet was also self-reported in the 46-year questionnaire ("Do you follow any specific diet: lactose-free, glutenfree, food allergy, diabetic, cholesterol-lowering, weight-loss, vegetarian, low-salt, other diet?"). The diets were not further defined in the questionnaire. Due to the small group sizes, the diets were combined as follows: lactose-free, gluten-free, weight-loss, vegetarian, other diet. As the population was coeval, we did not assess age as a confounder.

\section{Statistical analysis}

We administered and analyzed the data using SPSS software version 22 (IBM, Armonk, NY, USA). $p$ values of $<0.05$ were considered statistically significant. For categorical variables, we presented frequencies with percentages, and for continuous variables, means with standard deviations or medians with interquartile ranges, depending on the normality of the data. In the analysis of $\mathrm{Ca}$ and vertebral CSA, we used crude and multivariable generalized estimating equations (GEE) and linear regression models as specified below. GEE is a regressionbased statistical method and is more suitable for processing repeatedly measured and thus correlated data than traditional linear regression [36]. In GEE, we corrected for correlation using the "exchangeable" working correlation matrix. Where appropriate, the assumptions of the models were assured beforehand. Vertebral CSA $\left(\mathrm{mm}^{2}\right)$ was the continuous outcome variable in each model. We documented beta coefficients $(\beta)$ and their $95 \%$ confidence intervals (CI) from the models.

We analyzed $\mathrm{Ca}$ intake in both categorical and continuous forms. First, the association between Ca intake (adequate versus inadequate at the ages of 31 and 46) and vertebral CSA was analyzed using GEE. In the adjusted models, we used the corresponding 31-year and 46-year categorical vitamin D intake variables as covariates, among other covariates. Then, we analyzed longitudinal $\mathrm{Ca}$ intake (adequate, ascending, descending, inadequate) and vertebral CSA, using linear regression. In the adjusted models, we used the corresponding longitudinal vitamin D intake variable as a covariate, among other covariates. Lastly, we used GEE to analyze the association of $\mathrm{Ca}$ intake (continuous, $\mathrm{mg} /$ day) at the ages of 31 and 46 with vertebral CSA. In the adjusted models, we used the corresponding continuous 31-year and 46-year vitamin D intake variables as covariates, among other covariates. Due to the substantial sex discrepancy in vertebral CSA [26], we stratified all models by sex.

\section{Ethical considerations}

The study protocol followed the Declaration of Helsinki and was approved by the Ethics Committee of the Northern Ostrobothnia Hospital District. Participation was voluntary, and participants signed their informed consent at all stages.

\section{Results}

Of the 1064 individuals whose data we could evaluate, 56.4\% were women and $43.6 \%$ were men. Tables 1 and 2 show the background characteristics of the sample. Mean age at lumbar MRI was 46.8 years and mean BMI $26.5 \mathrm{~kg} / \mathrm{m}^{2}$; most individuals had attended school for 9 to 12 years, were nonsmokers, and did not follow a special diet. Adequate Ca intake ( $\geq 800 \mathrm{mg} /$ day at both time points) was reported by $58.6 \%$ of men and $47.7 \%$ women.

The distribution of vertebral CSA across the $\mathrm{Ca}$ intake categories, together with between-group comparisons, are shown in Table 3. When Ca intake was analyzed separately at the two time points, no differences were detected between individuals with adequate and inadequate intake. However, 
Table 1 General characteristics of the Northern Finland Birth Cohort 1966 subsample $(n=1064)$

\begin{tabular}{|c|c|c|}
\hline Variable & Men $(n=464)$ & Women $(n=600)$ \\
\hline Exact age at MRI, years ${ }^{\mathrm{a}}$ & $46.8(0.4)$ & $46.8(0.4)$ \\
\hline Body mass index at age $46^{\mathrm{a}}, \mathrm{kg} / \mathrm{m}^{2}$ & $26.8(3.7)$ & $26.2(5.0)$ \\
\hline \multicolumn{3}{|l|}{ Education, years } \\
\hline$<9^{\mathrm{b}}$ & $3.0(14)$ & $2.0(12)$ \\
\hline $9-12^{b}$ & $71.3(331)$ & $72.3(434)$ \\
\hline$>12^{\mathrm{b}}$ & $25.6(119)$ & $25.7(154)$ \\
\hline \multicolumn{3}{|l|}{ Smoking history } \\
\hline Non-smoker ${ }^{\mathrm{b}}$ & $51.1(237)$ & $61.5(369)$ \\
\hline Former $^{\mathrm{b}}$ & $33.4(155)$ & $23.2(139)$ \\
\hline Current $^{\mathrm{b}}$ & $15.5(72)$ & $15.3(92)$ \\
\hline \multicolumn{3}{|c|}{ Leisure-time physical activity at age 46 , times/week } \\
\hline$<1^{\mathrm{b}}$ & $26.5(123)$ & $22.7(136)$ \\
\hline $1^{\mathrm{b}}$ & $22.2(103)$ & $19.5(117)$ \\
\hline $2-3^{\mathrm{b}}$ & $36.4(169)$ & $41.7(250)$ \\
\hline$\geq 4^{\mathrm{b}}$ & $14.9(69)$ & $16.2(97)$ \\
\hline \multicolumn{3}{|l|}{ Diet at age 46} \\
\hline No specific $\operatorname{diet}^{\mathrm{b}}$ & $71.3(331)$ & $65.3(392)$ \\
\hline Lactose-free $^{\mathrm{b}}$ & $9.1(42)$ & $8.5(51)$ \\
\hline Gluten-free $^{\mathrm{b}}$ & $1.5(7)$ & $2.8(17)$ \\
\hline Weight-loss ${ }^{\mathrm{b}}$ & $1.9(9)$ & $5.2(31)$ \\
\hline Vegetarian $^{\mathrm{b}}$ & $1.3(6)$ & $3.8(23)$ \\
\hline Other $^{b}$ & $14.9(69)$ & $14.3(86)$ \\
\hline \multicolumn{3}{|l|}{ Dimensions of L4 at age 46} \\
\hline Cross-sectional area ${ }^{\mathrm{a}}, \mathrm{mm}^{2}$ & $1322.1(166.6)$ & $1052.6(130.3)$ \\
\hline
\end{tabular}

${ }^{\mathrm{a}}$ Mean (standard deviation), ${ }^{\mathrm{b}}$ Percentage (number of individuals). MRI magnetic resonance imaging

the longitudinal assessment of $\mathrm{Ca}$ intake (from age 31 to 46) revealed that women with inadequate $\mathrm{Ca}$ intake had smaller vertebral CSA than those with adequate intake (3.8\% difference in vertebral CSA, adjusted $p=0.009)$. No differences were detected among men. Ca intake was also assessed in its continuous form as a predictor of vertebral CSA (Supplementary Table 1); no statistically significant findings were obtained from either sex.

\section{Discussion}

Using a general population sample of 1064 middle-aged Northern Finns, this prospective study aimed to determine the association of dairy- and supplement-based $\mathrm{Ca}$ intake (from age 31 to 46) with vertebral size (age 46). Among women, inadequate $\mathrm{Ca}$ intake was associated with $3.8 \%$ smaller midlife vertebral CSA than adequate intake over the follow-up. Among men, Ca intake was not associated with vertebral CSA.
Table 2 Calcium and vitamin D intake among the Northern Finland Birth Cohort 1966 subsample $(n=1064)$

\begin{tabular}{|c|c|c|}
\hline Variable & Men $(n=464)$ & Women $(n=600)$ \\
\hline \multicolumn{3}{|l|}{ Calcium intake } \\
\hline At age $31^{\mathrm{a}}, \mathrm{mg} /$ day & $1170(780-1511)$ & $945(690-1241)$ \\
\hline$<800^{\mathrm{b}}$ & $25.9(120)$ & $38.5(231)$ \\
\hline$\geq 800^{\mathrm{b}}$ & $74.1(344)$ & $61.5(369)$ \\
\hline At age $46^{\mathrm{a}}, \mathrm{mg} /$ day & $1095(720-1425)$ & $945(720-1241)$ \\
\hline$<800^{\mathrm{b}}$ & $31.0(144)$ & $34.2(205)$ \\
\hline$\geq 800^{\mathrm{b}}$ & $69.0(320)$ & $65.8(395)$ \\
\hline \multicolumn{3}{|c|}{ Longitudinal $\mathrm{Ca}$ intake $\mathrm{c}^{\mathrm{c}}$ from age 31 to 46} \\
\hline Inadequate $\mathrm{e}^{\mathrm{b}, \mathrm{c}}$ & $15.5(72)$ & $20.3(122)$ \\
\hline Descending $^{\mathrm{b}, \mathrm{c}}$ & $15.5(72)$ & $13.8(83)$ \\
\hline Ascending ${ }^{\mathrm{b}, \mathrm{c}}$ & $10.3(48)$ & $18.2(109)$ \\
\hline Adequate $\mathrm{e}^{\mathrm{b}, \mathrm{c}}$ & $58.6(272)$ & $47.7(286)$ \\
\hline \multicolumn{3}{|l|}{ Vitamin D intake } \\
\hline At age $31^{\mathrm{a}}, \mu \mathrm{g} / \mathrm{day}$ & $\mathrm{n} / \mathrm{a}^{\mathrm{d}}$ & $\mathrm{n} / \mathrm{a}^{\mathrm{d}}$ \\
\hline$<10^{\mathrm{b}}$ & $97.6(453)$ & $98.7(592)$ \\
\hline$\geq 10^{\mathrm{b}}$ & $2.4(11)$ & $1.3(8)$ \\
\hline At age $46^{\mathrm{a}}, \mu \mathrm{g} / \mathrm{day}$ & $12.0(9.0-17.8)$ & $11.0(8.0-16.8)$ \\
\hline$<10^{\mathrm{b}}$ & $34.3(159)$ & $41.0(246)$ \\
\hline$\geq 10^{\mathrm{b}}$ & $65.7(305)$ & $59.0(354)$ \\
\hline \multicolumn{3}{|c|}{ Longitudinal vitamin D intake from age 31 to $46^{\mathrm{c}}$} \\
\hline Inadequate $\mathrm{e}^{\mathrm{b}, \mathrm{c}}$ & $33.6(156)$ & $40.5(243)$ \\
\hline Descending ${ }^{\mathrm{b}, \mathrm{c}}$ & $0.6(3)$ & $0.5(3)$ \\
\hline Ascending ${ }^{\mathrm{b}, \mathrm{c}}$ & $64.0(297)$ & $58.2(349)$ \\
\hline Adequate $^{\mathrm{b}, \mathrm{c}}$ & $1.7(8)$ & $0.8(5)$ \\
\hline
\end{tabular}

${ }^{\mathrm{a}}$ Median (interquartile range). ${ }^{\mathrm{b}}$ Percentage (number of individuals). ${ }^{\mathrm{c}}$ Longitudinal $\mathrm{Ca} /$ vitamin $\mathrm{D}$ intake categories were defined as follows: inadequate $(<\mathrm{RDI}$ at age 31 and 46$)$, descending $(\geq \mathrm{RDI}$ at age 31 and $<$ RDI at age 46 ), ascending ( $<$ RDI at age 31 and $\geq$ RDI at age 46), adequate $(\geq \mathrm{RDI}$ at age 31 and 46$) .{ }^{\mathrm{d}}$ Medians and interquartile ranges were not given for vitamin $\mathrm{D}$ at age 31 because the data were mostly based on categorical variables. $R D I$ recommended daily intake (for $\mathrm{Ca}, 800 \mathrm{mg}$ / day; for vitamin $\mathrm{D}, 10 \mu \mathrm{g} /$ day)

Investigations of $\mathrm{Ca}$ and bone morphology in the appendicular skeleton have been carried out previously (e.g., reports of larger femoral cross-sectional area [14-16] and enhanced femoral cortical parameters $[13,17])$. However, in these studies, the samples have consisted of mostly women, the results have shown low effect sizes, and the studied doses/cut-offs for $\mathrm{Ca}$ intake have varied. Importantly, few reports have addressed the axial skeleton and vertebral morphology. An Australian study [17] of 111 men aged $\geq 50$ years showed that the consumption of Ca-vitamin-D-fortified milk had no effect on vertebral geometry in a 2-year follow-up. In our study, neither the cut-off-based comparisons nor the continuous modeling of $\mathrm{Ca}$ intake yielded significant results among men. Despite the different study populations and the various methodological differences between the said study and ours, 


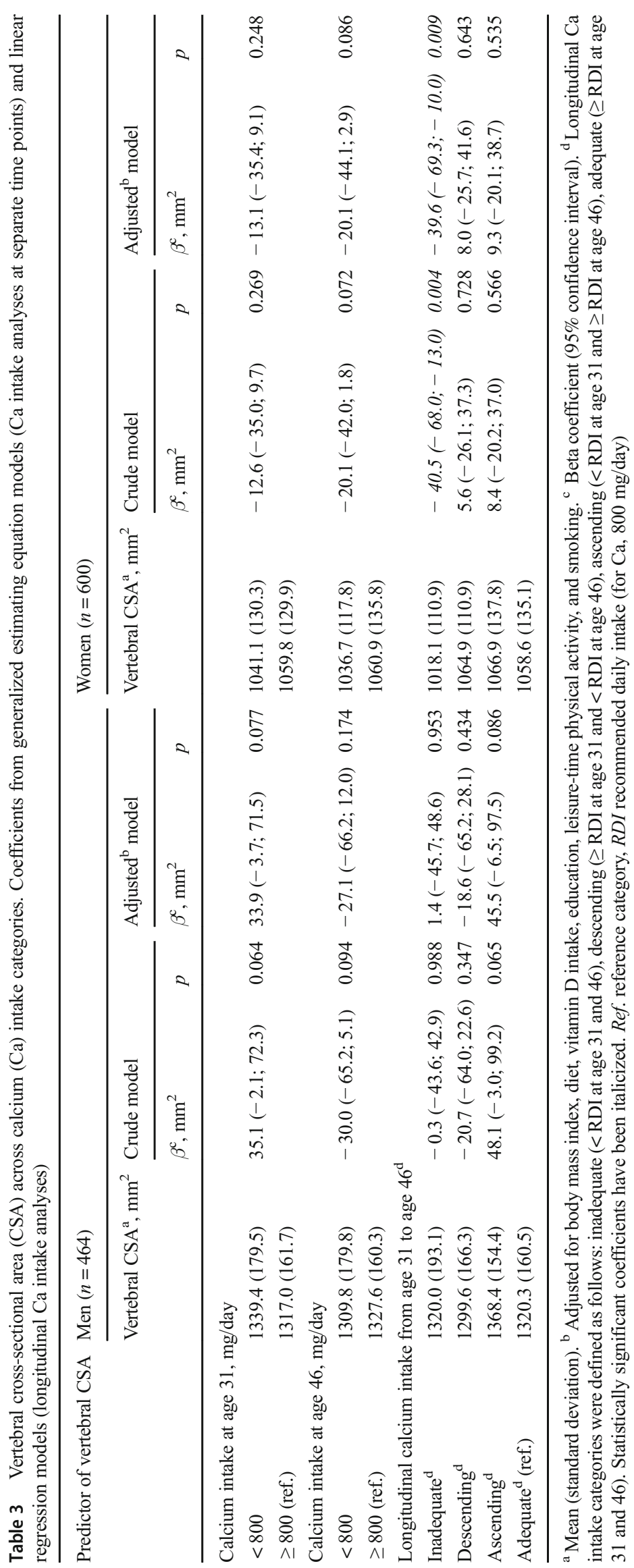


the present findings regarding men are in line with the previous report. As we observed significant results among women, future studies should confirm this sex discrepancy and investigate the potential underlying factors. However, it should be noted that our sample sizes for men were somewhat lower than those for women, particularly in the inadequate $\mathrm{Ca}$ intake group, which may explain the lack of statistical significance among men. Another explanation for the detected sex discrepancy may be the potential pregnancy-associated changes in bone metabolism, although in our previous study [37], we observed no association between pregnancy, or even multiple pregnancies, and maternal vertebral CSA or shape.

Among women, our models revealed that inadequate $\mathrm{Ca}$ intake from age 31 to 46 was associated with smaller vertebral CSA at age 46. As the cut-off for adequate $\mathrm{Ca}$ intake was chosen according to the local Finnish [33] and Nordic [34] nutrition recommendations, our findings underline the benefits of following these recommendations in terms of gaining and maintaining optimal vertebral CSA. Naturally, several other lifestyle factors are also associated with vertebral size [6-8] and should be accounted for in order to optimize one's vertebral size. In the time-point-specific models, we observed no association between $\mathrm{Ca}$ intake and vertebral CSA, indicating that $\mathrm{Ca}$ intake is likely to affect spinal health over a longer period of time.

Generally, small vertebral size increases susceptibility to morphometric vertebral fractures [4,5], indicating that studies that aim to reveal lifestyle-related determinants of vertebral size are of high relevance. However, it is not yet known whether this also applies to the more specific, reproducible, and incident fracture predictive morphological fractures that may be without dimensional differences but have cortical disruptions [38]. The incidence of osteoporotic fractures begins to increase after midlife, especially among women [39], justifying our investigation of the 46-year population. Although patients with an osteoporotic fracture apparently have inadequate dietary $\mathrm{Ca}$ (and vitamin D) intake [40], recent metaanalyses have questioned the routine use of $\mathrm{Ca}$ and vitamin D supplements among older people in terms of reaching higher bone mineral density (BMD) [41] and lower fracture risk [42]. The findings of the present study addressed neither vertebral BMD nor fracture history, but are suggestive of decreased spinal resilience among middle-aged women who have not achieved adequate $\mathrm{Ca}$ intake in adulthood.

The main strengths of our study were its large general population sample and longitudinal assessment of $\mathrm{Ca}$ intake in adulthood. The study population was representative of the general Northern Finnish population [19], and the 15-year follow-up period, from age 31 to age 46, was rather long. We were also able to control for the potential confounding effect of vitamin D intake on Ca. We obtained data on vertebral geometry from recent MRI scans using a validated approach [24] with high intra-rater reliability and low measurements errors [7]. We measured several dimensions to maximize measurement accuracy.

Our study also had limitations. With regard to our $\mathrm{Ca}$ variables, the approximation of $\mathrm{Ca}$ intake was based on dairy consumption and $\mathrm{Ca}$ supplements, and was therefore not fully exhaustive, although dairy products are widely used in the Finnish population [28]. As other sources yield relatively little of the daily Ca supply among Finns and more precise evaluation of these sources (e.g., the use of plant-based "milks" enriched with $\mathrm{Ca}$, nuts, seeds, soya) was not achievable, we decided to approximate $\mathrm{Ca}$ intake as presented. We also used self-reports to gather nutritional data, which is a potential source of bias, although the test-retest reliability of our questionnaire has shown to be high [43, 44]. For convenience, the questionnaires did not enquire about each food individually but in groups of similar food items, and this may have introduced inaccuracies to our $\mathrm{Ca}$ and vitamin $\mathrm{D}$ intake estimates. We were unable to take every source of calcium and vitamin D into account when calculating the intake estimates. Instead of self-reported vitamin D intake, the measurement of serum 25hydroxyvitamin $\mathrm{D}$ level would be an interesting target for further studies. The cutoffs for adequate $\mathrm{Ca}$ intake were chosen in accordance with local nutrition recommendations and previous literature [33, 34]. We used the general population reference values, as the study population was representative of the general Finnish population. As our nutritional data from childhood and adolescence were scarce, we were unable to provide $\mathrm{Ca}$ intake estimates for these time periods, although they may play an important role in the development of vertebral size. However, according to our recent study, vertebral dimensions and CSA undergo changes in adulthood [45], suggesting that later life is also relevant in this regard. In addition to $\mathrm{Ca}$, we acknowledge that a wide range of other relevant nutritional factors may affect vertebral size, e.g., protein and fat intake [10]. Unfortunately, we were unable to provide estimates for protein, fat, or total energy intake due to the structure of the food questionnaires. As for vertebral data, lumbar MRI scans were only obtained in midlife, which prevented us from assessing vertebral size in a longitudinal manner. We also specifically focused on vertebral geometry instead of structural or architectural parameters, which equally influence bone strength [5] and may be more easily affected by $\mathrm{Ca}$. This choice was made due to the lack of studies using vertebral size as outcome. We measured L4 because it was located in the middle of the lumbar MRI scans, with both axial and sagittal slices available. Vertebral geometry and strength seem to follow a stable pattern across the thoracic and lumbar spine [27], indicating that our results regarding L4 should be applicable across the thoracolumbar spine. Future studies should aim to compensate the limitations of our data.

We conclude that inadequate $\mathrm{Ca}$ intake $(<800 \mathrm{mg} /$ day $)$ in adulthood predicts small vertebral size and thus decreased spinal resilience among middle-aged women. Among men, there 
was no association between $\mathrm{Ca}$ intake and vertebral size. Future studies should confirm these findings and investigate the potential factors underlying the association of low Ca intake in women but not in men with smaller vertebral size. Moreover, although vertebral dimensions have been previously shown to predict morphometric vertebral fractures, it is not yet known whether this also applies to the more specific, reproducible and incident fracture predictive morphological fractures that may be without dimensional differences but have cortical disruptions.

Acknowledgements We thank all cohort members and researchers who participated in the 31- and 46-year studies. We also wish to acknowledge the work of the NFBC project center.

Funding information NFBC1966 received financial support from the University of Oulu (grant no. 65354, 24000692), the Oulu University Hospital (grant no. 2/97, 8/97, 24301140), the Finnish Ministry of Health and Social Affairs (grant no. 23/251/97, 160/97, 190/97), the National Institute for Health and Welfare, Helsinki, Finland (grant no. 54121), the Regional Institute of Occupational Health, Oulu, Finland (grant no. 50621, 54231), and the European Regional Development Fund (grant no. 539/2010 A31592). P. Oura received financial support from the Finnish Foundation for Nutrition Research (Ravitsemuksen tutkimussäätiö), the Vappu Uuspää Foundation (Vappu Uuspään säätiö), and the Päivikki and Sakari Sohlberg Foundation (Päivikki ja Sakari Sohlbergin säätiö). Open access funding provided by University of Oulu including Oulu University Hospital.

\section{Compliance with ethical standards}

Ethical approval All procedures performed in studies involving human participants were in accordance with the ethical standards of the institutional and/or national research committee and with the 1964 Helsinki declaration and its later amendments or comparable ethical standards.

Informed consent was obtained from all individual participants included in the study.

Conflict of interest The financial support received by P. Oura is specified in the Funding section. The remaining authors declare that they have no conflict of interest.

Open Access This article is distributed under the terms of the Creative Commons Attribution-NonCommercial 4.0 International License (http:// creativecommons.org/licenses/by-nc/4.0/), which permits any noncommercial use, distribution, and reproduction in any medium, provided you give appropriate credit to the original author(s) and the source, provide a link to the Creative Commons license, and indicate if changes were made.

\section{References}

1. Szulc P (2018) Vertebral fracture - diagnostic difficulties of a major medical problem. J Bone Miner Res 33(4):553-559

2. Chen P, Krege J, Adachi J et al (2009) Vertebral fracture status and the World Health Organization risk factors for predicting osteoporotic fracture risk. J Bone Miner Res 24(3):495-502

3. Ballane G, Cauley J, Luckey M et al (2017) Worldwide prevalence and incidence of osteoporotic vertebral fractures. Osteoporos Int 28(5):1531-1542
4. Ruyssen-Witrand A, Gossec L, Kolta S, Dougados M, Roux C (2007) Vertebral dimensions as risk factor of vertebral fracture in osteoporotic patients: a systematic literature review. Osteoporos Int 18(9):1271-1278

5. Bouxsein M, Karasik D (2006) Bone geometry and skeletal fragility. Curr Osteoporos Rep 4(2):49-56

6. Oura P, Junno J, Auvinen J et al (2018) Body mass index trajectories from birth to midlife and vertebral dimensions in midlife - the Northern Finland Birth Cohort 1966 study. JBMR Plus

7. Oura P, Paananen M, Niinimaki J et al (2016) Effects of leisure-time physical activity on vertebral dimensions in the Northern Finland Birth Cohort 1966. Sci Rep 6:27844

8. Oura P, Paananen M, Niinimaki J et al (2017) High-impact exercise in adulthood and vertebral dimensions in midlife - the Northern Finland Birth Cohort 1966 study. BMC Musculoskelet Disord $18(1): 433$

9. Plawecki K, Chapman-Novakofski K (2010) Bone health nutrition issues in aging. Nutrients 2(11):1086-1105

10. Sahni S, Mangano K, McLean R et al (2015) Dietary approaches for bone health: lessons from the Framingham Osteoporosis Study. Curr Osteoporos Rep 13(4):245-255

11. Abrams S (2011) Calcium and vitamin D requirements for optimal bone mass during adolescence. Curr Opin Clin Nutr Metab Care 14(6):605-609

12. Rizzoli R (2014) Nutritional aspects of bone health. Best Pract Res Clin Endocrinol Metab 28(6):795-808

13. Kim K, Choi S, Lim S et al (2014) Interactions between dietary calcium intake and bone mineral density or bone geometry in a low calcium intake population (KNHANES IV 2008-2010). J Clin Endocrinol Metab 99(7):2409-2417

14. Nurzenski M, Briffa N, Price R et al (2007) Geometric indices of bone strength are associated with physical activity and dietary calcium intake in healthy older women. J Bone Miner Res 22(3):416424

15. Jackson R, Wright N, Beck T et al (2011) Calcium plus vitamin D supplementation has limited effects on femoral geometric strength in older postmenopausal women: the Women's Health Initiative. Calcif Tissue Int 88(3):198-208

16. Uusi-Rasi K, Sievanen H, Pasanen M et al (2008) Influence of calcium intake and physical activity on proximal femur bone mass and structure among pre- and postmenopausal women. A 10-year prospective study. Calcif Tissue Int 82(3):171-181

17. Daly R, Bass S, Nowson C (2006) Long-term effects of calciumvitamin-D3-fortified milk on bone geometry and strength in older men. Bone 39(4):946-953

18. Rantakallio P (1988) The longitudinal study of the northern Finland birth cohort of 1966. Paediatr Perinat Epidemiol 2(1):59-88

19. Oura P (2017) Search for lifetime determinants of midlife vertebral size : emphasis on lifetime physical activity and early-life physical growth. Acta Univ Oul D 1418. Oulun yliopisto, Oulu

20. Oura P, Paananen M, Niinimaki J et al (2016) Effect of occupational physical activities on vertebral dimensions in midlife in the Northern Finland Birth Cohort 1966. Occup Environ Med 74(5): 351-356

21. Oura P, Paananen M, Ojaniemi M, Auvinen J, Junno JA, Karppinen J, Niinimäki J (2017) Effect of early life physical growth on midlife vertebral dimensions - The Northern Finland Birth Cohort 1966 study. Bone 101:172-178

22. Junno J, Paananen M, Karppinen J et al (2015) Age-related trends in vertebral dimensions. J Anat 226(5):434-439

23. Junno J, Paananen M, Karppinen J et al (2011) Influence of physical activity on vertebral size. Osteoporos Int 22(1):371-372

24. Junno J, Niskanen M, Nieminen M et al (2009) Temporal trends in vertebral size and shape from medieval to modern-day. PLoS One 4(3):e4836 
25. Peel N, Eastell R (1994) Diagnostic value of estimated volumetric bone mineral density of the lumbar spine in osteoporosis. J Bone Miner Res 9(3):317-320

26. Bogduk N (2012) Clinical and radiological anatomy of the lumbar spine, 5th edn. Churchill Livingstone, Edinburgh

27. Brinckmann P, Biggemann M, Hilweg D (1989) Prediction of the compressive strength of human lumbar vertebrae. Clin Biomech (Bristol, Avon) 4(Suppl 2):3-27

28. Agriculture and Agri-Food Canada (2015) Dairy products in Western Europe: global analysis report. Minister of Agriculture and Agri-Food, Ottawa, Canada

29. Mitrou P, Albanes D, Weinstein S et al (2007) A prospective study of dietary calcium, dairy products and prostate cancer risk (Finland). Int J Cancer 120(11):2466-2473

30. Finnish National Institute for Health and Welfare (201) Fineli: the National Food Composition Database in Finland. Available at: https://fineli.fi/fineli/en/index/. Accessed 2 Feb 2018

31. Sääksjärvi K, Reinivuo H (2004) Publications of the National Public Health Institute (B 15/2004): Ruokamittoja. Helsinki, National Public Health Institution

32. Helldán A, Raulio S, Kosola M et al (2013) Finravinto 2012 tutkimus - the national FINDIET 2012 survey. THL Raportti 16/ 2013. Helsinki, National Institute for Health and Welfare

33. Fogelholm M, Hakala P, Kara R et al (2014) Terveyttä ruoasta Suomalaiset ravitsemussuositukset 2014 (Finnish Nutrition Recommendations 2014$)$. Tampere, Valtion ravitsemusneuvottelukunta

34. Nordic Council of Ministers (2014) Nordic Nutrition Recommendations 2012 - Integrating nutrition and physical activity. Nordic Council of Ministers

35. Finnish Food Safety Authority (2018) Announcements and action plans: Fortified foods - vitamin D. Available at: https://www.evira. fi/en/foodstuff/healthy-diet/national-nutrition-council/ announcements-and-action-plans/. Accessed 14 June 2018
36. Twisk J (2003) Applied longitudinal data analysis for epidemiology. Cambridge University Press, Cambridge

37. Oura P, Paananen $M$, Auvinen J, Niinimäki J, Niinimäki $M$, Karppinen J, Junno JA (2018) Gravidity, parity and vertebral dimensions in the Northern Finland Birth Cohort 1966. Spine (Phila Pa 1976) 43(18):E1102-E1108

38. Lentle B, Berger C, Probyn L et al (2018) Comparative analysis of the radiology of osteoporotic vertebral fractures in women and men: cross-sectional and longitudinal observations from the Canadian multicentre osteoporosis study (CaMos). J Bone Miner Res 33(4): 569-579

39. Ensrud K (2013) Epidemiology of fracture risk with advancing age. J Gerontol A Biol Sci Med Sci 68(10):1236-1242

40. Yoon D, Lee Y, Ha Y et al (2016) Inadequate dietary calcium and vitamin D intake in patients with osteoporotic fracture. J Bone Metab 23(2):55-61

41. Tai V, Leung W, Grey A et al (2015) Calcium intake and bone mineral density: systematic review and meta-analysis. BMJ 351: h4183

42. Zhao J, Zeng X, Wang J et al (2017) Association between calcium or vitamin D supplementation and fracture incidence in community-dwelling older adults: a systematic review and metaanalysis. JAMA 318(24):2466-2482

43. Laitinen J, Ek E, Sovio U (2002) Stress-related eating and drinking behavior and body mass index and predictors of this behavior. Prev Med 34(1):29-39

44. Kelloniemi H, Ek E, Laitinen J (2005) Optimism, dietary habits, body mass index and smoking among young Finnish adults. Appetite 45(2):169-176

45. Autio E, Oura P, Karppinen J, Paananen M, Niinimäki J, Junno JA (2018) Changes in vertebral dimensions in early adulthood - a 10year follow-up MRI-study. Bone In press

Publisher's note Springer Nature remains neutral with regard to jurisdictional claims in published maps and institutional affiliations. 